\title{
To evaluate the effects of dexmedetomidine on intraocular pressure and haemodynamic changes in response to laryngoscopy and tracheal intubation
}

\author{
Tanuja, Shobha Purohit, Amit Kulshreshtha
}

\begin{abstract}
Background: The most important prerequisites for neurosurgeries are brain relaxation, need of stable haemodynamics with less fluctuation in intracranial pressure and speedy recovery from anaesthesia. Endotracheal intubation is the major stressful stimuli that can elicit a marked pressor response. Various drugs have been used to attenuate these reflexes. Dexmedetomidine, a highly selective alpha 2-adrenoceptor agonist, have neuroprotective, cardioprotective, and sedative effects so it is potentially useful during neuroanaesthesia. This is a prospective randomised control trial carried out to see whether administration of Dexmedetomidine prior to intubation can attenuate the various haemodynamic responses, intraocular pressure (IOP) and the requirement of induction dose of propofol in control and study group. Materials and Methods: Fifty patients (ASA grade I, 2) scheduled for intracranial tumour surgeries were divided into two groups (25 each). Group D received Dexmedetomidine $0.8 \mu \mathrm{g} / \mathrm{kg}$ i.v. over 10 mins and group C received $20 \mathrm{ml}$ saline. Anaesthesia induced with Propofol, dose adjusted using bispectral index monitor. The groups were compared with IOP, Heart rate (HR), Mean arterial pressure (MAP), and dose of Propofol required for induction. Results: Groups were well matched for their demographic data and pre-operative. IOP in both the eyes decreases significantly after premedication and remained below baseline even after $10^{\text {th }}$ min of intubation in group D while in Group C; it increased significantly after intubation and remained above baseline. The difference between groups was also statistically significant. HR and MAP decreased significantly in patients of group $D$ compared to group $C(P<0.05)$. Patients were more haemodynamicaly stable at all time points after premedication in group $D(P<0.05)$. Propofol requirements for induction was lesser in group $D(P<0.05)$. Bradycardia and hypotension incidences were higher in group $D$. Conclusion: Dexmedetomidine premedication decreases the sympathoadrenal effect on IOP and haemodynamic parameters during laryngoscopy/intubation and decreases the requirement of propofol for induction of general anaesthesia.
\end{abstract}

Key words: $\alpha_{2}$-agonists, dexmedetomidine, general anaesthesia, intraocular pressure, intracranial tumour surgery, haemodynamic response, tracheal intubation

\section{INTRODUCTION}

The concept of neuroanaesthesia includes several principles, but the most important is perioperative

\begin{tabular}{|l|l|}
\hline \multicolumn{2}{|c|}{ Access this article online } \\
\hline Quick Response Code: & Website: \\
\hline & www.jnaccjournal.org \\
\cline { 2 - 2 } & \\
\hline & \\
\hline
\end{tabular}

haemodynamic stability. The haemodynamic response to laryngoscopy and intubation during surgery leads to abrupt increase in arterial blood pressure which may cause bleeding or oedema in the operating field. The low arterial pressure predisposes the patients to cerebral ischaemia, with disturbed autoregulation of the cerebral blood flow (CBF), which is often impaired near tumours or traumatised areas. After surgery, hypertension may predispose the patient to postoperative intracranial haematoma.

The potential for life-threatening complications associated with the haemodynamic and intraocular

Department of Anaesthesia, Sawai ManSingh Medical College, Jaipur, Rajasthan, India

Address for correspondence:

Dr. Tanuja, Department of Anaesthesia, Sawai ManSingh Medical College, Jaipur, Rajasthan, India. Email- trivedi.princesstanu.tanuja@gmail.com 
pressure (IOP) responses to laryngoscopy and intubation is also well documented. ${ }^{[1]}$ IOP may be indirect reflection of intracranial pressure (ICP) as described by few studies. ${ }^{[2-4]}$ A diversity of results exist about the protective measures against the haemodynamic and the catecholamine responses to laryngoscopy and intubation, but no single anaesthetic technique has become generally accepted as being effective in preventing or attenuating these responses. Many techniques have been recommended. The drugs which were used were either partially effective or they produced other undesirable effects on the patients. ${ }^{[5]}$ The drugs for optimisation of IOP and haemodynamic responses aim to stabilise heart rate and blood pressure during laryngoscopy and intubation in order to prevent any rise in myocardial work load and oxygen demand as well as to preserve the perfusion of vital organs.

It is desirable to use a drug with rapidly recognisable and easily treatable adverse effects. The procedure should be simple so that it can be recommended as a routine practice. It is logical to select an agent which would prevent or minimise the laryngopharyngeal stimulation by the intubation process or an agent which would block the sympathetic activity associated with it.

Dexmedetomidine, a highly selective $\alpha_{2}$ agonist, shorter acting and more specific alternative to Clonidine, is expected to have less side effects and better safety profile than the latter. It has been used by many researchers for attenuation of haemodynamic response to tracheal intubation as well as extubation in various doses and along with other anaesthetic regimens. ${ }^{[6-8]}$ Majority of effects caused by Dexmedetomidine are due to the stimulation of $\alpha_{2}$ adrenoreceptors located in CNS and spinal cord. These receptors are involved in sympatholysis, sedation, and antinociceptive effects of $\alpha_{2}$ adrenoreceptors. The aim of the present study is to determine the effect of dexmedetomidine on the IOP and haemodynamic responses to direct laryngoscopy and tracheal intubation in patients undergoing intracranial tumour surgery.

\section{MATERIALS AND METHODS}

This prospective randomised study was conducted between November 2012 and April 2013.

Fifty ASA-I/II patients of age 20-50 years, undergoing elective intracranial tumour surgery were enrolled after approval from the institutional ethics committee and written informed consent of the patient. Patients having compromised renal, pulmonary and cardiac status, patients having any acute or chronic eye disease or taking any medication which can alter IOP, patients with anticipated difficult intubation, and those having known allergy to anaesthetic agents used were excluded from the study.
The research methodology was prospectively randomised with the help of chit in box method and patients were divided into two groups: Group D (Dexmedetomidine group) and Group C (Control group).

On arrival in the operation theatre, baseline parameters $\left[\mathrm{SpO}_{2}\right.$, Pulse rate (PR), Systolic blood pressure (SBP), Diastolic blood pressure (DBP) and Mean arterial pressure (MAP) were recorded. Two peripheral lines with 18/20-G cannula secured. Dorsalis pedis arterial cannulation was done for invasive blood pressure (IBP) monitoring. Proparacaine $0.5 \%$ eye drop, (1 drop in each eye) instilled 1 minute before measurement of base line IOP. Patients were premedicated with midazolam $(0.02 \mathrm{mg} / \mathrm{kg}$ i.v. $)$, glycopyrrolate $(0.005 \mathrm{mg} / \mathrm{kg}$ i.v.) and fentanyl (2 mcg/ $/ \mathrm{kg}$ i.v.). Dexmedetomidine $0.8 \mathrm{mcg} / \mathrm{kg}$ i.v. (in 20-ml saline) or placebo (normal saline $20 \mathrm{ml}$ i.v.) were given slowly over 10 minutes in groups D and group $\mathrm{C}$, respectively. Haemodynamic parameters and IOP were measured at end of infusion. General anaesthesia was induced with propofol, keeping BIS between 40 and 50 and trachea intubated with vecuronium $(0.12 \mathrm{mg} / \mathrm{kg}$ i.v.). Haemodynamic parameters and IOP were measured 1 minute after induction of anaesthesia, after intubation and then at 1, 3, 5 and 10 minutes of intubation. Central venous line (subclavian vein) inserted after induction of anaesthesia. Anaesthesia was maintained with i.v. propofol, $40 \% \mathrm{O}_{2} / 60 \% \mathrm{~N}_{2} \mathrm{O}$ and vecuronium $(0.02 \mathrm{mg} / \mathrm{kg})$. At the end of the surgical procedure neuromuscular block was reversed with neostigmine $0.05 \mathrm{mg} / \mathrm{kg}$ i.v. and glycopyrrolate $0.01 \mathrm{mg} / \mathrm{kg}$ i.v. Intraoperative complications, if any, were noted. Patients shifted to recovery room and any immediate post-operative complication e.g. nausea, vomiting, shivering, respiratory depression, sedation, restlessness, hypotension, bradycardia were noted and managed.

We defined following terms for the study:

1. Hypotension - defined as SBP $<20 \%$ of baseline value or $90 \mathrm{~mm}$ of $\mathrm{Hg}$, whichever is lower.

2. Hypertension defined as SBP $>20 \%$ of baseline value or $150 \mathrm{~mm}$ of $\mathrm{Hg}$, whichever is higher.

3. Tachycardia defined as HR $>25 \%$ of baseline value.

4. Bradycardia defined as $\mathrm{HR}<50 \mathrm{bpm}$.

\section{Statistical analysis}

Statistical analysis was done using Primer software and XL- Stat. All the quantitative data were summarised in the form of Mean \pm SD. The difference between mean values of both groups was analyzed using Student's $t$ test. All the qualitative data were summarised in the form of proportions. The differences between proportions were analyzed using Chi-square test. The levels of significance and $\alpha$ - error were kept $95 \%$ and $5 \%$, respectively, for all statistical analyses. $P<0.05$ were considered significant. 


\section{RESULTS}

All the data is expressed as mean and standard deviation. The two groups were comparable in patient characteristics with respect to age, gender, mean weight and ASA physical status $(P>0.05)$ [Table 1]. Mean baseline variables were comparable in both the groups [Figure 1].

Decrease in IOP was observed in group D following dexmedetomidine injection $(P=0.001)$ [Figure 2]. Following tracheal intubation, IOP increased in both groups, but it dropped below baseline in group D. However, IOP did not return to baseline in the controls, even at 10 minutes.

In group $\mathrm{C}$ the basal mean IOP was $21.01 \mathrm{mmHg}$ which remain unaffected by premedication but decreased significantly at induction to $19.45 \mathrm{mmHg}$. It rises significantly just after intubation to $26.47 \mathrm{mmHg}$ (increase of $25.3 \%$ from basal value). At 1,3,5 mins mean IOP values were well above baseline and it remained above baseline even after 10 mins of intubation. In group D basal mean IOP was $22.02 \mathrm{mmHg}$. It decreases significantly to $19.56 \mathrm{mmHg}$ after dexmedetomidine premedication and it decreases further to $16.67 \mathrm{mmHg}$ after induction with propofol. Just after intubation mean IOP rises to $18.03 \mathrm{mmHg}$ but it was well below basal value $(18.1 \%$

Table 1: Demographic characteristics

\begin{tabular}{lccc}
\hline Variables & Group C & Group D & P value \\
\hline Age (years) & $38.8 \pm 10.24$ & $35.96 \pm 9.46$ & NS \\
Gender $(\mathrm{M} / \mathrm{F})$ & $14 / 11$ & $12 / 13$ & - \\
Weight $(\mathrm{kg})$ & $58 \pm 8.4$ & $57.96 \pm 10.54$ & $\mathrm{NS}$ \\
ASA grade $(\mathrm{I} / \mathrm{II})$ & $19 / 6$ & $20 / 5$ & - \\
Duration of & $275.8 \pm 81.68$ & $276.4 \pm 83.01$ & NS \\
surgery (mins) & & & \\
\hline
\end{tabular}

ASA = American Society of Anaesthesiology (M/F-Male/Female), NS = Not significant

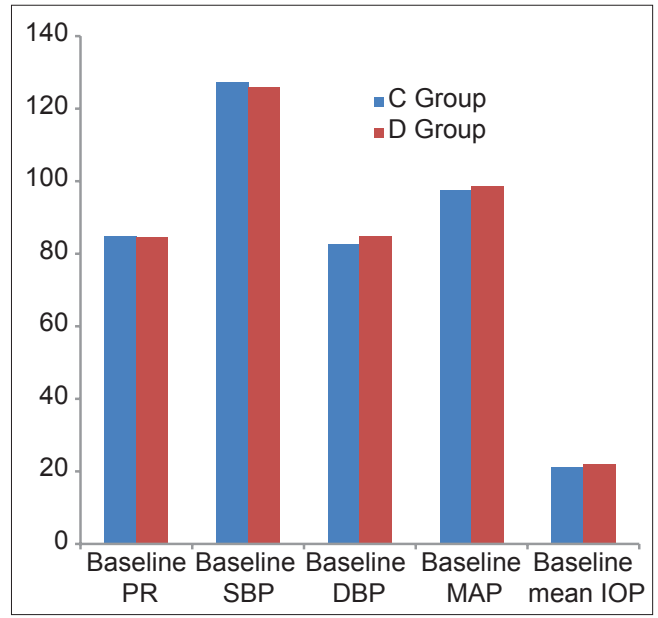

Figure 1: Comparison of mean baseline variables fall from the basal value). The IOP continued to be below the basal value even after 10 mins of intubation. Basal IOP of both the group were comparable $(P>0.05)$ but highly significant difference $(P<0.001)$ were observed between groups at all time points thereafter till 10 mins.

After administering dexmedetomidine, decrease in HR was observed in group D, while significant increase in HR was recorded following intubation in the control group [Figure 3]. Similarly, a fall in MAP following dexmedetomidine injection in group $\mathrm{D}$ and increase in MAP above the baseline following intubation in the group $C$ was recorded [Figure 4]. The mean induction dose of propofol required for induction was $128.6 \pm 15.51 \mathrm{mg}$ in group $\mathrm{C}$ and in group $\mathrm{D}$ dose required was $91.8 \pm 20.41 \mathrm{mg}$. Total propofol requirements for induction is $29 \%$ less in patients of group D than in patients of group C. No drug-related adverse events were observed. In dexmedetomidine group, two patients $(8 \%)$ developed bradycardia and hypotension was noted in four patients $(16 \%)$, which were managed by glycopyrrolate and fluid boluses, respectively. In Control group, no patients developed bradycardia, but hypotension occurred in two patients (8\%) at $1 \mathrm{~min}$ after induction which was managed by infusing intravenous fluids. The difference between incidence of bradycardia and hypotension between the groups are statistically not significant $(P=0.14$ and $P=0.38$, respectively).

\section{DISCUSSION}

This study was designed to study the effect of dexmedetomidine on haemodynamics and IOP during tracheal intubation and its anaesthetic sparing effect for induction of general anaesthesia. Intracranial hypertension is one of the most important therapeutical problems in the neuroanaesthesia and neurosurgery. Measurement of ICP is the gold standard

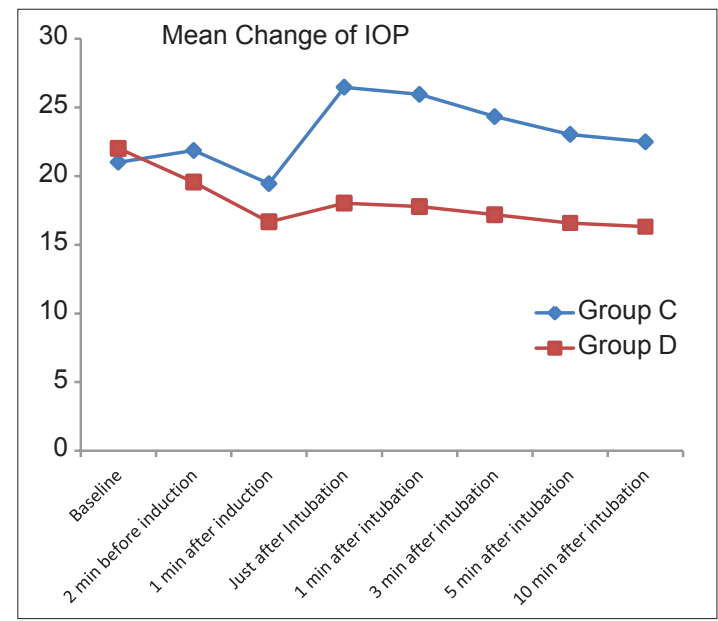

Figure 2: Comparison of mean IOP in both groups 
Tanuja, et al.: Dexmedetomidine in intracranial tumour surgery

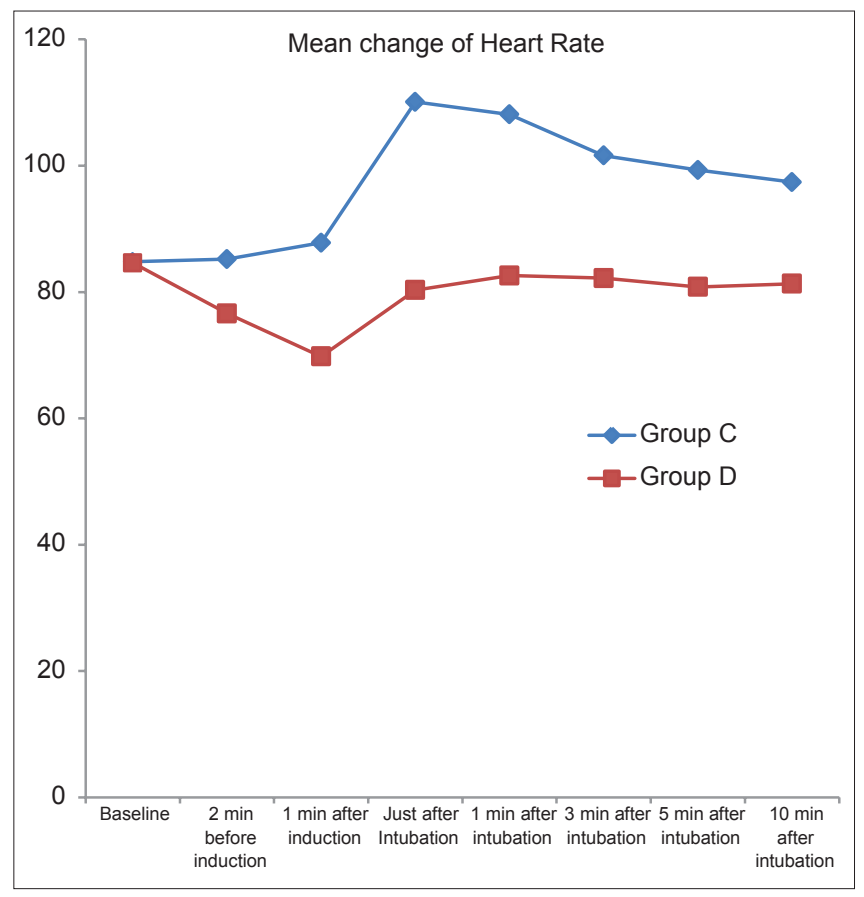

Figure 3: Trends of Heart rate in both the groups

in neurosurgical care. The monitoring of intracranial pressure is a well-known problem and it is performed by intraventricular or intraparenchymal ICP measurement or by lumber puncture. Some authors claim that it is possible to estimate ICP in an alternative way using intraocular pressure as an indirect surrogate for ICP. ${ }^{[2-4]}$ But it is still a matter of debate. Increase in mean arterial pressure may abruptly increase cerebral blood flow if autoregulation limit is crossed which may further increase ICP. Dexmedetomidine reduces cerebral blood flow and cerebral metabolic requirement of oxygen but its effect on ICP is not yet clear.

IOP is determined by extraocular muscle tone, scleral rigidity, vascularity of the orbit and production and outflow of aqueous humour. Temporary variations in pressure are usually well-tolerated in normal eyes but even transient episodes of increased IOP in patients with underlying low ophthalmic artery pressure may jeopardise retinal perfusion and cause retinal ischaemia. Increases intraocular pressure in the setting of an open globe may cause drainage of aqueous or extrusion of vitreous through the wound. The findings of our study were in terms of: HR, MAP, IOP, induction dose of propofol and adverse event related.

Dexmedetomidine prevented the increase in IOP after laryngoscopy and tracheal intubation. The maximum decrease in IOP was $26 \%$ in dexmedetomidine group after induction of anaesthesia. After induction of anaesthesia with propofol, IOP decreased significantly in the placebo group also, but it was statistically significantly above baseline values after laryngoscopy and tracheal intubation.

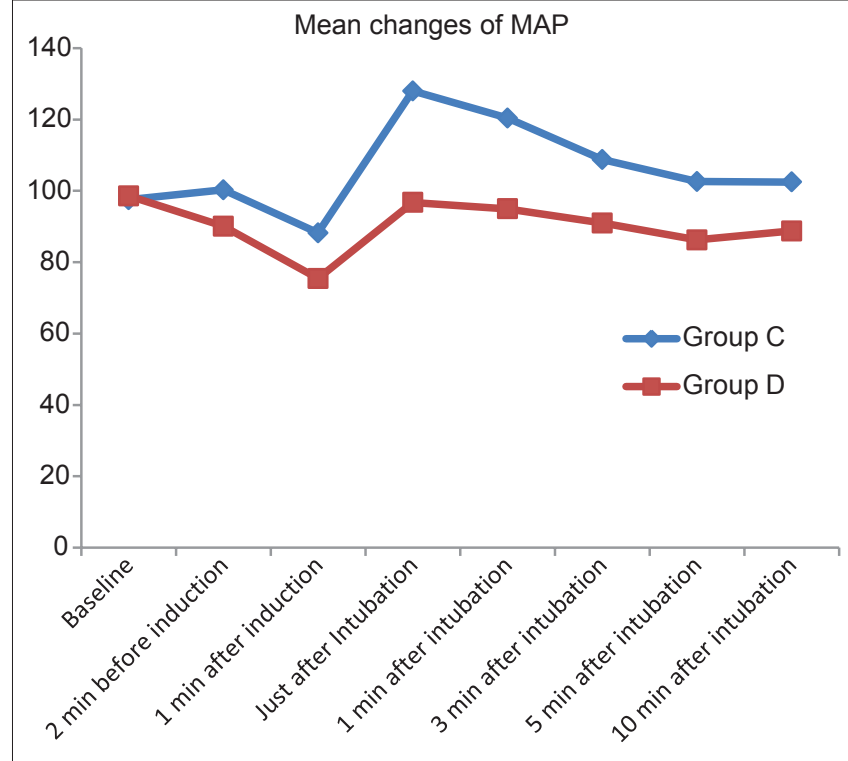

Figure 4 :Comparison of Mean change in MAP in both the groups

The findings of our study are in accordance with studies by Jaakola et al. ${ }^{[9]}$, Pal et al. ${ }^{[10]}$ and Mowafi et al..$^{[11]}$ who also found a rise in IOP following laryngoscopy and intubation in placebo group and consistently decrease in IOP after dexmedetomidine administration in study group. Ayoglu et al. ${ }^{[12]}$, Selcuk et al. ${ }^{[13]}$, and Virkkila et al. ${ }^{[14]}$ also noted a decrease in IOP from baseline after Dexmedetomidine loading dose, similar to our study.

Dexmedetomidine increases the haemodynamic stability by altering the stress-induced sympathoadrenal responses to intubation during surgery and during emergence from anaesthesia. Jaakola et al. ${ }^{[9]}$ in their study concluded that dexmedetomidine attenuates the increase in heart rate and blood pressure during intubation. The dose used for this study was $0.6 \mathrm{mcg} / \mathrm{kg}$, which is almost similar to the dose used by us.

Scheinin et al ${ }^{[15]}$ studied the effect of dexmedetomidine on tracheal intubation, required dose of induction agent and preoperative analgesic requirements. They concluded that the required dose of thiopentone was significantly lower in the dexmedetomidine group and the drug attenuated the haemodynamic responses to intubation. The concentration of noradrenaline in mixed venous plasma was lesser in the dexmedetomidine group.

Lawrence et al. ${ }^{[16]}$ found that a single dose of $2 \mathrm{mcg} / \mathrm{kg}$ of dexmedetomidine before induction of anaesthesia attenuated the haemodynamic response to intubation as well as that to extubation. Bradycardia was observed at the $1^{\text {st }}$ and $5^{\text {th }}$ min after administration while we observed hypotension and bradycardia at $11^{\text {th }}$ minute of dexmedetomidine administration. This might have been due to bolus administration. 
Jaakola et al..$^{[9]}$, Lawrence et al. ${ }^{[16]}$, Laha et al. ${ }^{[17]}$ found anaesthetic sparing effect of dexmedetomidine.

Laha et al. ${ }^{[17]}$ studied the effect of intravenous dexmedetomidine on the dose of propofol requirement for induction. They found that a single dose of $1 \mathrm{mcg} / \mathrm{kg}$ of dexmedetomidine as a premedication adjuvant causes reduction of $42 \%$ of induction dose of propofol.

The dose of dexmedetomidine in our study was $0.8 \mathrm{mcg} / \mathrm{kg}$ as an infusion over $10 \mathrm{~min}$. It is a well-known fact that depression of sympathetic response against laryngoscopy and intubation is an important advantage, especially in high-risk patients. The hypotension and bradycardia caused by dexmedetomidine, theoretically, could limit its usage in patients on beta blocker therapy. There are few studies used dexmedetomidine as an anaesthetic adjuvant in neurosurgical patients. ${ }^{[18]} \mathrm{A}$ biphasic cardiovascular response has been described after the administration of dexmedetomidine. ${ }^{[19]} \mathrm{A}$ bolus of $1 \mathrm{mcg} / \mathrm{kg}$ results in a transient increase in arterial blood pressure and reflex decrease in heart rate in young healthy patients. Initial response is due to alfa2 receptor stimulation of vascular smooth muscle. This response can be markedly decreased by slow infusion over $10 \mathrm{~min}$. In our study, this effect was not noticed due to the slow infusion of the drug over $10 \mathrm{~min}$.

\section{LIMITATIONS}

We did not measure the plasma norepinephrine levels which could precisely predict the suppression of sympathetic response to intubation. Secondly effect of maintenance infusion of dexmedetomidine on intraoperative haemodynamics and extubation response could be studied in neurosurgical patients.

We conclude that the preinduction administration of single dose dexmedetomidine in the dose of $0.8 \mathrm{mcg} / \mathrm{kg}$ decreases the magnitude of stress-induced sympathoadrenal effect on IOP and on haemodynamic parameters during laryngoscopy and intubation and it also decreases the requirement of dose of propofol for induction of general anaesthesia.

\section{REFERENCES}

1. Latto IP. Management of difficult intubation. In: Latto IP, Vaughan RS, editors. Difficulties in Tracheal Intubation. London: WB Saunders Company; 1997. p. 107-60.

2. Salman MS. Can intracranial pressure be measured non-invasively? Lancet 1997;350:1367.

3. Lashutka MK, Chandra A, Murray HN, Phillips GS, Hiestand BC. The relationship of intraocular pressure to intracranial pressure. Ann Emerg Med 2004;43:585-91.

4. Lehman RA, Krupin T, Podos SM. Experimental effect of intracranial hypertension upon intraocular pressure. J Neurosurg 1972;36:60-6.
5. Roy S, Rudra A, Gupta K, Mondal T, Chakravorty S. Attenuation of cardiovascular response to laryngoscopy and tracheal intubation with oral clonidine (Arkamine). Ind J Anaesth 1993;41:62-5.

6. Aksu R, Akin A, Bicer C, Esmaoglu A, Tosun Z, Boyaci A. Comparison of the effects of dexmedetomidine versus fentanyl on airway reflexes and hemodynamic responses to tracheal extubation during rhinoplasty: A double blind, randomized control study. Curr Ther Res 2009;10:209-20.

7. Suparto S, Flores OC, Layusa CA. A randomized controlled trial on the effectiveness of dexmedetomidine versus fentanyl in attenuating the sympathetic response to direct laryngoscopy and endotracheal intubation. Indones Digit J 2010;60:126-32.

8. Menda F, Koner O, Sayin M, Ture H, Imer P, Aykac B. Dexmedetomidine as an adjunct to anesthetic induction to attenuate hemodynamic response to endotracheal intubation in patients undergoing fast-track CABG. Ann Card Anaesth 2010;13:16-21.

9. Jaakola ML, Ali-Melkkila T, Kanto J, Kallio A, Scheinin H, Scheinin M. Dexmedetomidine reduces intraocular pressure, intubation response and anaesthetic requirements in patients undergoing ophthalmic surgery. Br J Anaesth 1992;68:570-5.

10. Pal CK, Ray M, Sen A, Hajra B, Mukherjee D, Ghanta AK. Changes in intraocular pressure following administration of Suxamethonium and endotracheal intubation: Influence of dexmedetomidine premedication. Indian J Anaesth 2011;55:573-7.

11. Mowafi HA, Aldossary N, Ismail SA, Alqutiani J. Effect of dexmedetomidine premedication on the intraocular pressure changes after succinylcholine and intubation. $\mathrm{Br} \mathrm{J}$ Anaesth 2008;100:485-9.

12. Ayoglu H, Altunkaya H, Ozer Y, Yapakci O, Ozkocak I, Oz O, et al. Dexmedetomidine sedation during cataract surgery under regional anaesthesia. Br J Anaesth 2007;99:448.

13. Selcuk M, Kabukcu H, Duranoglu Y, Sahin N, Titiz TA. The Dexmedetomidine infusion on intra-ocular pressure and sedation in catract surgery. Eur J Anaesthesiol 2005;22:15.

14. Virkkila M, Ali-Melkkila T, Kanto J, Turunen J, Scheinin H. Dexmedetomidine as intramuscular premedication for day-case cataract surgery. A comparative study of Dexmedetomidine, Midazolam and placebo. Anaesthesia 1994;49:853-8.

15. Scheinin B, Lindgren L, Randell T, Scheinin H, Scheinin M. Dexmedetomidine attenuates sympathoadrenal responses to tracheal intubation and reduces the need for thiopentone and preoperative fentanyl. $\mathrm{Br}$ J Anaesth 1992;68:126-31.

16. Lawrence $C J$, De Lange $S$. Effects of a single preoperative dexmedetomidine dose on isoflurane requirements and peri-operative haemodynamic stability. Anaesthesia 1997;52:736-44.

17. Laha A, Ghosh S, Sarkar S. Attenuation of sympathoadrenal responses and anaesthetic requirement by dexmedetomidine. Anaesth Essays Res 2013;7:65-70.

18. Tanskenen PE, Kytta JV, Randell TT, Aantaa RE. Dexmedetomidine as an anesthetic adjuvant in patients undergoing intracranial tumour surgery: A double blind, randomized and placebo-controlled study. $\mathrm{Br} \mathrm{J}$ Anaesth 2006;97:658-65.

19. Bloor BC, Ward DS, Belleville JP, Maze M. Effects of intravenous dexmedetomidine in humans. II. Haemodynamic changes. Anaesthesiology 1992;77:1134-42.

How to cite this article: T, Purohit S, Kulshreshtha A. To evaluate the effects of dexmedetomidine on intraocular pressure and haemodynamic changes in response to laryngoscopy and tracheal intubation. J Neuroanaesthesiol Crit Care 2014;1:178-82.

Source of Support: Nil, Conflict of Interest: None declared. 